Letter to the Editor

\title{
Bilateral ipilimumab-induced posterior uveitis following treatment for metastatic choroidal melanoma
}

\author{
Alexander XJ Tan FRANZCO, ${ }^{1}$ Amelia Ang GradDipClinPharm, ${ }^{2}$ William Gordon \\ Campbell FRANZCO ${ }^{2}$ and David CA Fabinyi FRANZCO ${ }^{2}$
}

1. The Royal Victorian Eye and ear Hospital, Melbourne, Victoria, Australia

2. The Victorian Comprehensive Cancer Centre, Melbourne, Victoria, Australia

Correspondence: Alexander Xiong Jian Tan, The Royal Victorian Eye and Ear Hospital, 32 Gisborne St, East Melbourne, VIC 3002, Australia

Received 22 January 2018; accepted 3 March 2018

Conflict of interest: None

Funding sources: None

This is the author manuscript accepted for publication and has undergone full peer review but has not been through the copyediting, typesetting, pagination and proofreading process, which may lead to differences between this version and the Version of Record. Please cite this article as doi: 10.1111/ceo.13197

This article is protected by copyright. All rights reserved. 
Ipilimumab is a CTLA-4 monoclonal antibody that amplifies T-cell activation and response to melanoma. It is approved to treat unresectable or metastatic melanoma. Immune-related adverse events are common (up to $90 \%$ of patients), and include colitis, hypophysitis, hypothyroidism, hepatitis and dermatitis. ${ }^{1} 1.3 \%$ of patients suffer from ocular side effects, such as scleritis, anterior uveitis and Grave's-type ophthalmopathy. ${ }^{2}$ This report presents a novel case of bilateral posterior uveitis in a patient receiving ipilimumab for metastatic choroidal melanoma and summarises the literature regarding treatment options for patients with ocular immune-related adverse events.

A 27-year-old female presented with a choroidal melanoma in her right eye, which was treated with a $20 \mathrm{~mm}$ Ruthenium plaque. There was complete regression of the tumour, but she subsequently developed cystoid macular oedema as a result of radiation retinopathy. This responded to intravitreal aflibercept and her acuity returned to $6 / 5$.

She developed systemic metastatic disease 3 years following brachytherapy and was treated with ipilimumab. She then presented with decreased vision of 6/9.5 in each eye after the third dose. The anterior chamber was quiet and there were no cells or haze in the vitreous. Fundus examination revealed bilateral pale chorioretinal lesions, which on optical coherence tomography appeared as atypical intraretinal cysts in addition to extensive architectural changes in the retina from the outer plexiform layer to the ellipsoid zone (Figure 1).

Figure 1: A) Optos colour image of the right macula, showing scars from previous treatment. B) Optos colour image of the left macula. Optical coherence tomography scans through the $C$ ) right, and $D$ ) left macula. 
Fluorescein angiogram showed cystoid macular oedema and foci of leakage consistent with choroiditis, in addition to vascular leakage in the inferior retina secondary to radiation retinopathy from the previous brachytherapy (Figure 2).

Figure 2: Wide-field fluorescein angiography of the right and left eyes.

The patient concurrently developed a skin reaction and an autoimmune hepatitis while the uveitis was still active. In consultation with the patient's oncologist, the decision was made to not pursue further cycles. A short course of intravenous methylprednisolone therapy was instituted, followed by oral prednisolone, which resulted in resolution of ocular inflammation over 6 weeks and a return of vision to $6 / 4.8$ bilaterally. Unfortunately, the patient passed away shortly thereafter due to progressive metastatic omental disease.

Ipilimumab can trigger a systemic autoimmune response, with only $1-2 \%$ of patients developing ocular side effects, which include episcleritis, conjunctivitis, anterior uveitis, Vogt-Koyanagi-Harada-like syndrome, optic neuritis and a thyroid-like orbitopathy. ${ }^{3}$ These are typically treated with systemic corticosteroids and withdrawal of therapy. Refractory cases may require additional immunosuppression, including intravenous immunoglobulin, infliximab and plasmapheresis. ${ }^{1}$

We report here a patient who developed multiple immune-related adverse events, including posterior uveitis and hepatitis. To our knowledge this is the first reported case of bilateral choroiditis with cystoid macular oedema and outer retinal cavitation from ipilimumab therapy for metastatic choroidal melanoma. A previous case report has described bilateral choroidopathy and serous retinal detachments after 4 cycles of ipilimumab for cutaneous melanoma. ${ }^{4}$ Choroidal findings in ipilimumab-related 
uveitis may share the same pathophysiology as ipilimumab-related vasculopathies reported elsewhere in the body. ${ }^{5}$

This case, along with the current literature, suggests that the onset of severe ocular inflammation may necessitate discontinuation of ipilimumab and treatment with systemic corticosteroids for preservation of visual function. 


\section{REFERENCES}

1. Kumar V, Chaudhary N, Garg M, Floudas CS, Soni P, Chandra AB. Current Diagnosis and Management of Immune Related Adverse Events (irAEs) Induced by Immune Checkpoint Inhibitor Therapy. Frontiers in pharmacology. 2017;8:49.

2. Horvat TZ, Adel NG, Dang TO, Momtaz P, Postow MA, Callahan MK, et al. Immune-Related Adverse Events, Need for Systemic Immunosuppression, and Effects on Survival and Time to Treatment Failure in Patients With Melanoma Treated With Ipilimumab at Memorial Sloan Kettering Cancer Center. Journal of clinical oncology : official journal of the American Society of Clinical Oncology. 2015;33(28):3193-8.

3. Hager T, Seitz B. Ocular side effects of biological agents in oncology: what should the clinician be aware of? OncoTargets and therapy. 2014;7:69-77.

4. Mantopoulos D, Kendra KL, Letson AD, Cebulla CM. Bilateral Choroidopathy and Serous Retinal Detachments During Ipilimumab Treatment for Cutaneous Melanoma. JAMA ophthalmology. 2015;133(8):965-7.

5. Manousakis G, Koch J, Sommerville RB, El-Dokla A, Harms MB, Al-Lozi MT, et al. Multifocal radiculoneuropathy during ipilimumab treatment of melanoma. Muscle \& nerve. 2013;48(3):440-4. 

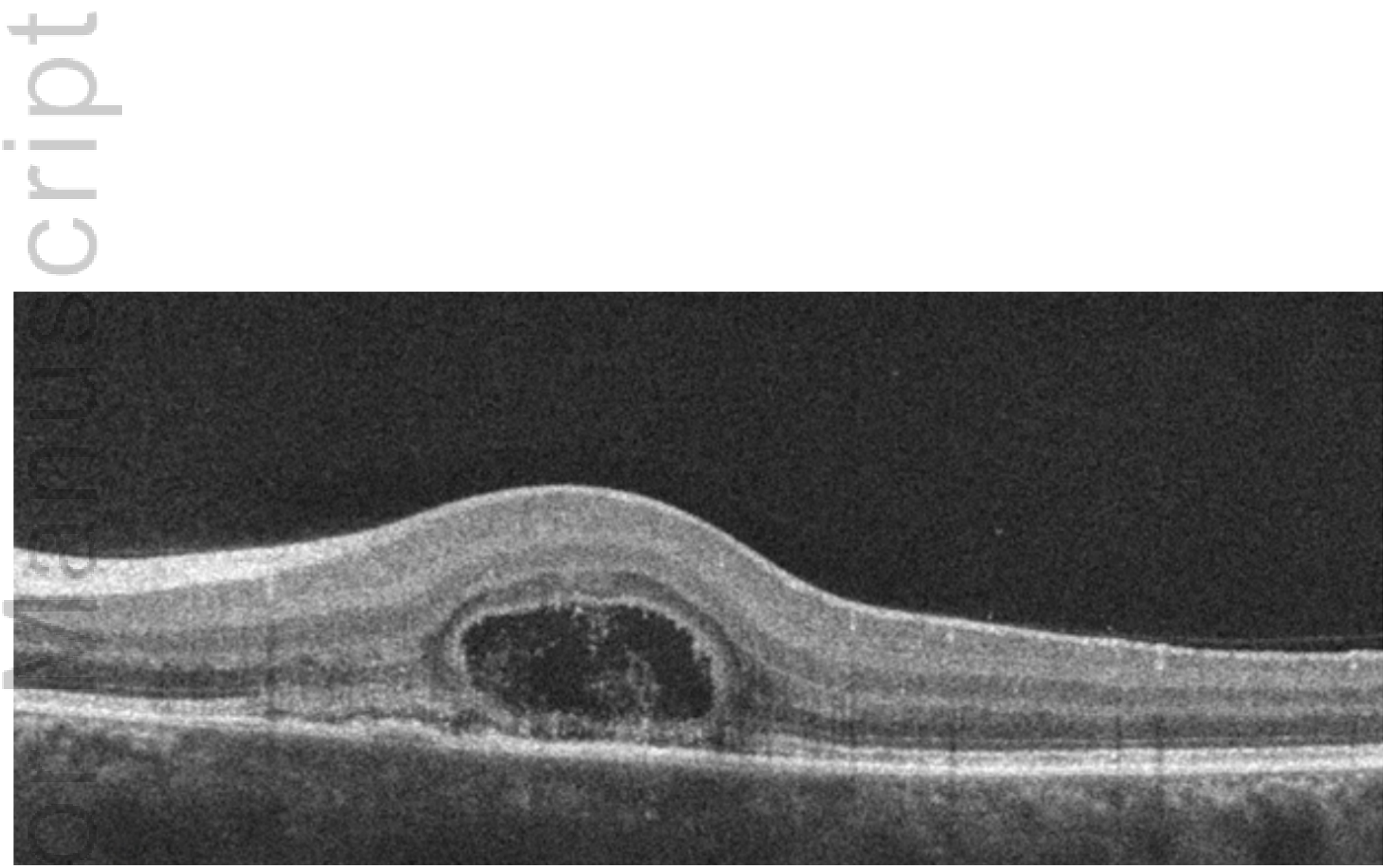

CE0-18-01-0075 figure 1c.tiff

This article is protected by copyright. All rights reserved. 


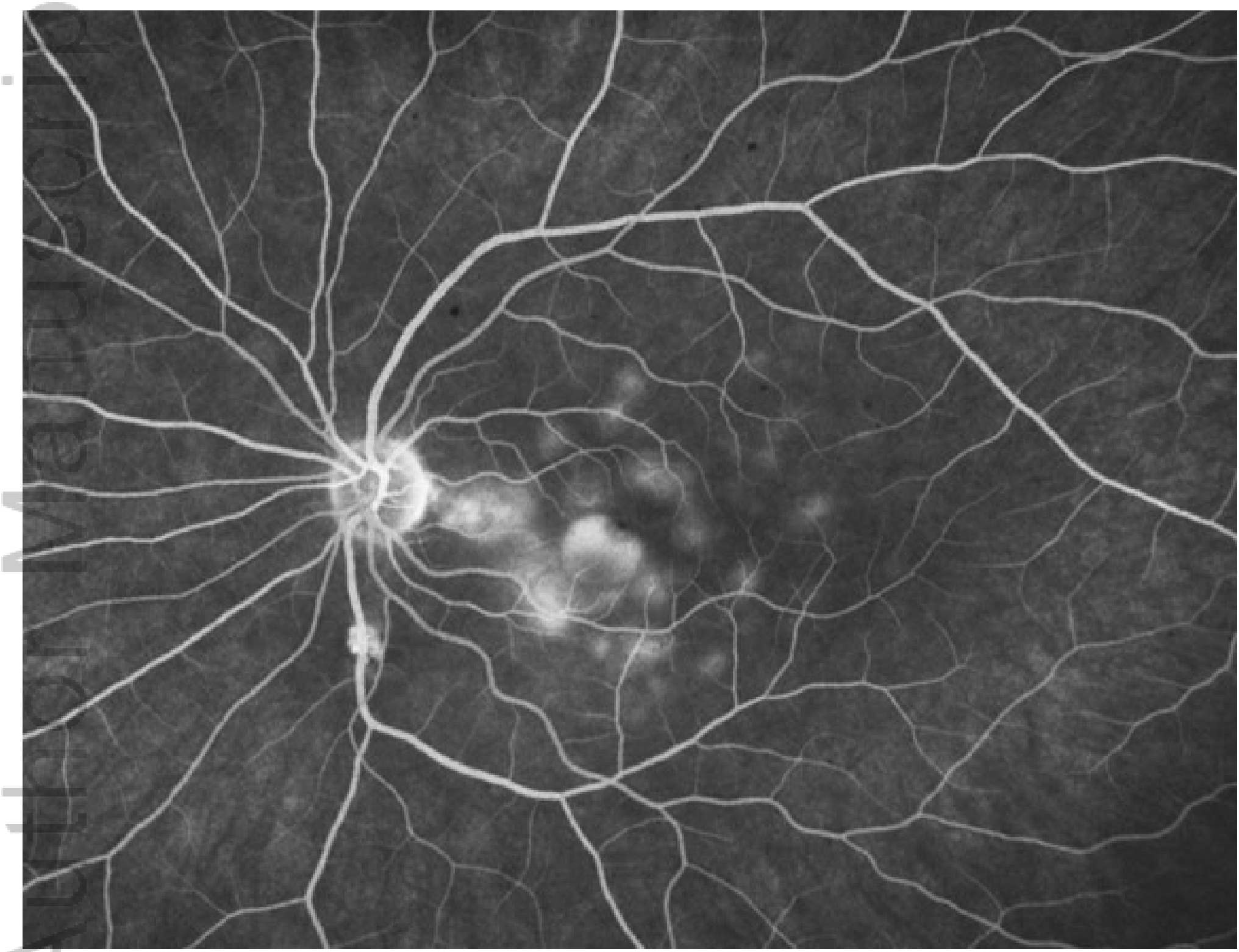

CE0-18-01-0075 figure 2 left.jpg

This article is protected by copyright. All rights reserved. 


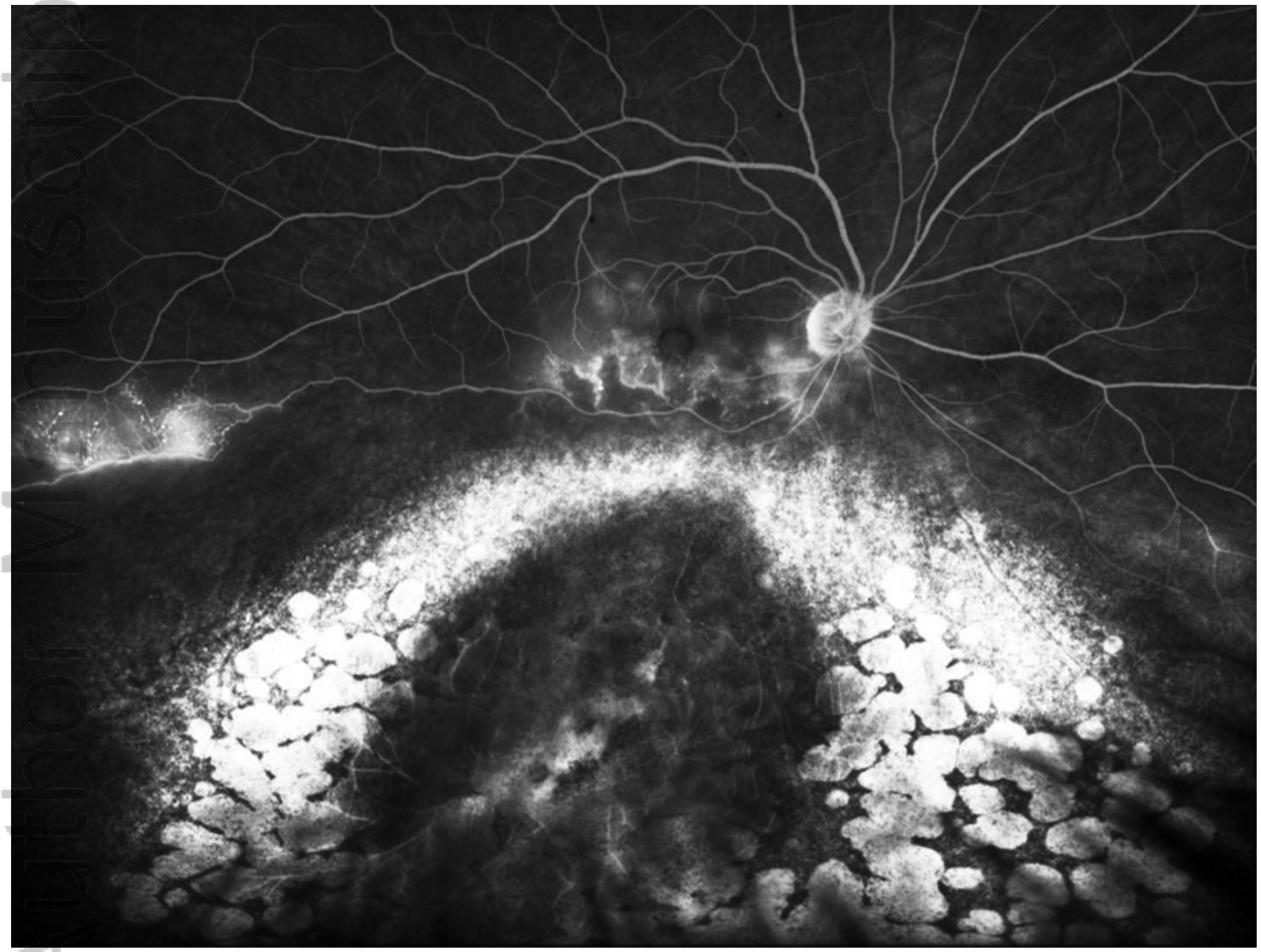

CE0-18-01-0075 figure 2 right.jpg

This article is protected by copyright. All rights reserved. 


\section{University Library}

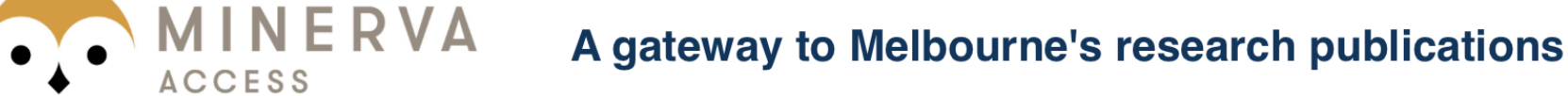

Minerva Access is the Institutional Repository of The University of Melbourne

Author/s:

Tan, AX;Ang, A;Campbell, WG;Fabinyi, DC

Title:

Bilateral ipilimumab-induced posterior uveitis following treatment for metastatic choroidal melanoma.

Date:

2018-09

\section{Citation:}

Tan, A. X., Ang, A., Campbell, W. G. \& Fabinyi, D. C. (2018). Bilateral ipilimumabinduced posterior uveitis following treatment for metastatic choroidal melanoma.. Clin Exp Ophthalmol, 46 (7), pp.819-821. https://doi.org/10.1111/ceo.13197.

Persistent Link:

http://hdl.handle.net/11343/283911 